\title{
OS DESAFIOS PARA A IMPLANTAÇÃO DE UM ÓRGÃO AMBIENTAL MUNICIPAL: RESULTADOS DA GESTÃO DA AMAPA 2017- 2019
}

\author{
Edilson Holanda Costa Filho' \\ Jefferson de Sousa Brito ${ }^{2}$ \\ Francisco Márcio Cavalcante Pinheiro ${ }^{3}$ \\ Marilangela da Sila Sobrinho ${ }^{4}$ \\ RESUMO
}

Com a criação da Resolução COEMA № 07/2019 foi possível os municípios cearenses, caso desejassem, exercerem a gestão ambiental local. O presente artigo, portanto, traz a cronologia de estruturação da Autarquia de Meio Ambiente de Pacatuba (AMAPA) e, através dessa experiência, objetiva apresentar os desafios para implantação de um órgão ambiental municipal. A partir das experiências dos servidores da AMAPA, de análise de documentos e dos relatórios de produtividade da autarquia entre os anos de 2017 e 2019, foi possível observar que o principal entrave para a criação do órgão foi o político. O comprometimento do poder executivo local foi necessário para que todas as outras variáveis (legislativa, técnica, estrutural e financeira) pudessem se alinhar e fazer existir um órgão ambiental de fato. Quanto a produtividade, no período considerado, observou-se um crescimento do número de licenças emitidas, com destaque para a tipologia Autorização Ambiental. Quanto ao monitoramento, o município utiliza o RAMA, um relatório entregue, anualmente, pelo empreendimento licenciado, com informações que subsidiam a análise da regularidade da instalação e operação. Em relação a fiscalização, a principal infração observada foi ausência de licença. Quanto a arrecadação, os valores foram $R \$ 300.571,45$, com licenciamento, $R \$ 69.030,04$, com fiscalização, $R \$$ $37.887,08$, com monitoramento e $\mathrm{R} \$ 54.928,94$, com compensação ambiental. Concluiu-se ser benéfico para os municípios a gestão ambiental municipal, principalmente por conta da autonomia em relação ao Estado e maior atenção aos interesses locais. A capacitação e a valorização dos servidores aparecem como fundamental para sustentabilidade do órgão.

Palavras-chave: Gestão Ambiental Local; Órgão Ambiental. Autarquia; AMAPA.

\footnotetext{
${ }^{1}$ Mestre em Engenharia Química pela Universidade Federal do Ceará (UFC) e especialista em Engenharia Ambiental e Saneamento Básico pelo Centro Universitário Estácio do Ceará; Servidor público do Estado do Ceará da Superintendência do Meio Ambiente (SEMACE). Email: edilsonholanda@gmail.com

${ }^{2}$ Mestre em Engenharia Civil pela Universidade Federal do Ceará (UFC), especialista em Recursos Hídricos pelo Instituto Federal do Ceará (IFCE) e doutorando em Desenvolvimento e Meio Ambiente (PRODEMA-UFC); Servidor público da Autarquia de Meio Ambiente do Município de Pacatuba/Ceará (AMAPA). Email: brito.jefferson@gmail.com

${ }^{3}$ Graduação em Engenharia Química pela Universidade Federal do Ceará (UFC); Servidor público da Secretaria de Meio Ambiente de Itaitinga/Ceará. Email: fmcpce@yahoo.com.br

${ }^{4}$ Mestre em Climatologia e Aplicações nos Países da Comunidade de Países de Língua Portuguesa e África pela Universidade Estadual do Ceará (UECE) e doutoranda em Desenvolvimento e Meio Ambiente (PRODEMA-UFC); Servidor público do Estado do Ceará da Superintendência do Meio Ambiente (SEMACE). Email mari1000silva@gmail.com
} 


\title{
THE CHALLENGES FOR IMPLEMENTING A MUNICIPAL ENVIRONMENTAL AGENCY: RESULTS FROM AMAPA MANAGEMENT 2017-2019
}

\begin{abstract}
With the resolution COEMA № 07/2019 it was possible for municipalities from Ceará, if they wished, to exercise local environmental management. The present article, therefore, brings the chronology of structuring the Autarchy of Environment of Pacatuba (AMAPA) and, through this experience, aims to present the challenges for the implantation of a municipal environmental agency. From interviews with AMAPA's employees, from document analysis and from the productivity reports between 2017 and 2019, it was possible to observe that the main obstacle to the creation of the agency was the political one. The commitment of the local executive power was necessary so that all other variables (legislative, technical, structural and financial) could align and make the environmental body exist. As for productivity, there was an increase in the number of licenses issued, with emphasis on the Environmental Authorization typology. As for monitoring, the municipality uses the RAMA, a report delivered annually by the licensed enterprise, with information that supports the analysis of the regularity of the installation and operation. In relation to inspection, the main infraction observed was the absence of a license. As for the collection, the amounts were $R \$ 300,571.45$, with licensing, $R \$ 69,030.04$, with inspection, $R \$$ $37,887.08$, with monitoring and $\mathrm{R} \$ 54,928.94$, with environmental compensation. It was concluded that municipal environmental management is beneficial for municipalities, mainly due to the autonomy in relation to the State and greater attention to local interests. The training and valorization of civil servants appear as fundamental for the organ's sustainability.
\end{abstract}

Keywords: Local Environmental Management; environmental agency Autarchy; AMAPA.

\section{INTRODUÇÃO}

No Brasil, o licenciamento ambiental é exigido para a instalação e operação de empreendimentos, que utilizam recursos naturais e/ou tenham o potencial degradador ao meio ambiente e desse modo causam impactos ambientais.

Alguns estados brasileiros iniciaram o procedimento do licenciamento na década de 1970, que foi posteriormente incorporado à legislação ambiental, sendo um dos instrumentos de gestão da Política Nacional de Meio Ambiente, através da Lei Federal № 6.938 em 1981. 
O licenciamento possui caráter preventivo, cujas funções resumidamente estão relacionadas à disciplinar e regulamentar o acesso e utilização dos recursos naturais e prevenir danos ambientais (ARAÚJO, 2019, p. 43).

Em 1988 esse instrumento de gestão foi consolidado, através do Art. 225 da Constituição Federal do Brasil e posteriormente regulado pela Lei Complementar $N^{\circ}$ 140/2011, que possibilitou a gestão ambiental descentralizada e concedeu autonomia para os municípios licenciarem as atividades de impacto local, desde que atendessem aos critérios básicos técnicos e legais exigidos (FERLA, 2012, p. 10).

De acordo com Alencar (2018, p.13), a descentralização do licenciamento ambiental é um desafio, pois as demandas locais progridem e os órgãos ambientais municipais devem estar preparados para atendê-las, com estrutura administrativa compatível às necessidades, que assegurem a redução dos impactos potenciais, decorrentes dos empreendimentos em fase de instalação e operação.

Goldmeier (2017, p.8) afirma que no licenciamento municipal, a administração pode ter o auxílio da população local e isso pode contribuir para o melhor direcionamento dos recursos e ações, colaborando para o desenvolvimento local sustentável e promover menores impactos ao meio ambiente, no entanto, alguns municípios brasileiros carecem de apoio e capacitação técnica, dentre outras prioridades.

Já os relatos de Araújo (2019) descrevem sobre as dificuldades da municipalização do licenciamento, relacionadas à falta de recursos e legislação consistente, que são suportes necessários para a atuação dos técnicos perante as irregularidades.

Por sua vez, os estudos de Machado (2018, p.39) indicam, que alguns municípios brasileiros estão aptos para exercer o licenciamento, contendo em sua estrutura órgão ambiental capacitado, legislação ambiental sólida, processos de informatização e conselhos municipais, no entanto alguns carecem de falta de estrutura e gestão na área. 
No Estado do Ceará foi necessária a definição sobre impacto local e estabelecimento de parâmetros para que o licenciamento ambiental fosse assumido pelos municípios. Assim, foi editada a Resolução № 07/2019, pelo Conselho Estadual de Meio Ambiente (COEMA). Atualmente são 42 municípios que dispõem de órgãos ambientais municipais aptos a licenciar, isso após apresentarem comunicação oficial sobre o desempenho da competência, para realizar o licenciamento em âmbito local, em obediência ao $\S 2^{\circ}$ do art. $7^{\circ}$, da referida norma.

Nesse contexto, destaca-se o município de Pacatuba, que iniciou suas atividades de licenciamento local a partir de 2017. Assim, não diferentemente de inúmeros outros, apresentou ao longo do processo de implantação do seu órgão ambiental inúmeros desafios, que foram ou estão sendo sanados com 0 amadurecimento técnico, administrativo e político dos steakholders, envolvidos na temática ambiental municipal: sociedade civil, usuários e poder público.

A Autarquia de Meio Ambiente de Pacatuba (AMAPA) foi criada como o órgão responsável pela gestão local do meio ambiente, assim realizando as ações de fiscalização, monitoramento e licenciamento de empreendimentos com impacto local.

A partir da experiência do município de Pacatuba, objetiva-se conhecer e descrever os principais obstáculos enfrentados na constituição de um órgão ambiental municipal. Em seguida, almeja-se conhecer as dificuldades enfrentadas pelo órgão ambiental municipal na execução de suas atividades. Ao apresentar esse panorama, busca-se fornecer aos municípios brasileiros um indicativo das possíveis dificuldades existentes no processo de instalação e operação de um órgão ambiental municipal, de modo que os interessados tenham um conhecimento prévio das etapas que poderão percorrer.

Como objetivos específicos que permitem a compreensão aprofundada deste trabalho destacam-se: descrever o histórico de implantação da AMAPA; descrever 0 atual processo de operação da autarquia; quantificar licenças ambientais e autos de infração do período de janeiro de 2017 a dezembro de 
2019 da AMAPA; e identificar as principais deficiências dos processos administrativos do órgão.

\section{FUNDAMENTAÇÃO TEÓRICA}

\subsection{CONSTITUIÇÃO BRASILEIRA}

A Constituição do Brasil de 1988 (CRFB/88), a Constituição Cidadã, é a primeira Carta magna do Brasil a dedicar um capítulo próprio à questão ambiental, assim alçando-o a categoria de direito fundamental ao não poder ser dissociado da vida. O núcleo normativo é o artigo 225, com seus parágrafos e incisos que constituem o Capítulo VI, Título VIII da CRFB/88.

Carvalho (2005, p.5) esclarece que o artigo 225 é construído por três conjuntos de normas: norma-princípio, ou norma-matriz, no caput do artigo é garantidora do meio ambiente equilibrado a todos; no parágrafo primeiro, os instrumentos de garantia da efetividade do direito no caput; e, determinações particulares, que são pormenorizações da Constituição, de extensão analítica.

Por outro lado, CRFB/88 nos apresenta ao longo do seu texto importantes artigos que estabeleceram o marco para a formação tripartite da gestão ambiental entre União, Estados, Distrito Federal e Municípios. Nela, os artigos 21 e 22 apresentaram, respectivamente, a competência material ${ }^{5}$ exclusiva e a competência legislativa ${ }^{6}$ privativa da União. A competência material comum da União, Estado, Distrito Federal e Municípios é apresentada no artigo 23 (FILHO, 2013, p.11).

A competência legislativa concorrente da União, Estado e Distrito Federal é citada no artigo 24, além da suplementar dos Estados e dos Municípios §2‥ E, finalmente, no artigo 30 a competência indicativa dos Municípios, além da suplementar, no inciso II (CARVALHO, 2005, p.2).

\footnotetext{
${ }^{5}$ É o dever-poder de pôr em prática os comandos e as prerrogativas.

${ }^{6}$ É a capacidade de editar leis e atos normativos primários.
} 


\section{sunisul}

\subsection{POLÍTICA NACIONAL DE MEIO AMBIENTE}

Apesar da CRFB/88 ser, hierarquicamente, o mais elevado instrumento legal do arcabouço jurídico brasileiro, é a Lei Federal n 6.938, de 31 de agosto de 1981, que dispõe sobre a Política Nacional de Meio Ambiente, que traz para a sociedade, entre muitas outras, a definição de licenciamento ambiental como procedimento administrativo realizado pelo órgão competente para licenciar a instalação, ampliação e operação de atividades e empreendimentos que utilizem recursos naturais, sejam potencialmente poluidores ou que possam causar degradação ambiental (PANTA, 2006, p. 25 apud FERLA, 2012, p. 15).

O caráter vanguardista da Política Nacional de Meio Ambiente - PNMA permitiu a sua recepção na Constituição, basicamente, em sua integralidade. A PNMA institui fundamentos que lastrearam toda a legislação, que a seguiu com a introdução dos seguintes marcos: Sistema Nacional de Meio Ambiente SISNAMA; competências do Conselho Nacional de Meio Ambiente; Estudo de Impacto Ambiental e Relatório de Impacto Ambiental; criação do licenciamento ambiental e estabelecimento das responsabilidades e penalidades impostas aos empreendedores ou atividades, que degradem o ambiente ou prejudiquem a saúde e o bem-estar humano (CEARÁ, 2017).

Contudo, para os municípios, a PNMA apresentou um conflito com a municipalização da gestão ambiental em sua plenitude, pois trazia a concepção da responsabilidade de licenciamento ambiental apenas aos entes federal e estadual. No entanto, com a publicação da Lei Complementar nº 140/2011, alterou-se de forma clara e objetiva essa compreensão limitante e, a partir dela, as competências das esferas estadual e federal ganharam os caracteres supletivos e subsidiários, respectivamente, quando ainda não há o órgão ambiental municipal e quando ele já existe, porém carecendo de capacidade e autonomia (CEARÁ, 2017, p. 23).

\subsection{LEI COMPLEMENTAR № 140/2011}

A Lei Complementar nํ 140, de 8 de dezembro de 2011, doravante LC nº 140/2011, cumpriu a tarefa de dirimir qualquer dúvida em relação a competência 
municipal para execução das ações administrativas previstas em seu artigo 9º, sobre o licenciamento ambiental de atividades de impacto local. Ao regular os incisos III, VI e VII do caput e o parágrafo único do artigo 23 da CRFB/88, a LC no 140/2011 indicou que os municípios possuem autonomia para no âmbito local construir e executar sua política ambiental, desde que em acordo com as demais esferas, mas principalmente garantindo a possibilidade de licenciar e fiscalizar as atividades e empreendimento com caráter local ${ }^{7}$.

Ao se estabelecer o conceito de impacto local, esse não pode ser confundido com o interesse apenas do município, mas que os efeitos dos impactos ambientais são preponderantes no município. Assim Carvalho (2005, p.7) esclarece que tanto a União quanto o Estado tem interesse, mas não na proporção do interesse local. A LC n 140/2011 buscou equilibrar a atuação dos entes federativos e evitar conflitos tornando a gestão ambiental mais eficiente e reforçando o ideal cooperativo entre os entes federativos (MOURA, 2017, p.84).

Nascimento (2018) em memorável avaliação da definição de impacto local e a avaliação do modelo de descentralização do licenciamento ambiental apresenta a importância da LC n 140/2011 para dirimir qualquer dúvida razoável quanto à autonomia dos municípios, uma vez que, até a sua publicação questionamentos eram apontados sobre a constitucionalidade da autonomia diante da Resolução CONAMA nํㅜ237/1997, pois havia a expressa exigência que o tema fosse regulamentado por lei complementar.

\subsection{ORGANIZAÇÃO DOS ÓRGÃOS AMBIENTAIS MUNICIPAIS}

A definição das condicionantes para a criação de órgãos ambientais municipais foi apresentada na LC n 140/2011, artigo 5º, parágrafo único, que considera um órgão ambiental capacitado aquele que possui técnicos próprios ou em consórcio, devidamente habilitados e em número compatível com a demanda das ações administrativas a serem delegadas. Contudo, essa

\footnotetext{
${ }^{7} \mathrm{Na}$ prática, os Conselhos Estaduais estabelecem uma listagem de atividades e empreendimentos considerados como de impacto local, segundo critérios de porte e potencial poluidor, que podem ser licenciadas pelos municípios (NASCIMENTO, 2018, p. 19).
} 


\section{sunisul}

descrição se tornou deveras superficial o que exigiu que os Estados construíssem critérios mais restritivos e claros com a intenção de sanar eventuais dúvidas.

Nascimento (2018, p.51) ao analisar a construção de todas as regulamentações estaduais sobre o tema, identificou que de forma unânime, apenas os critérios de órgão ambiental capacitado e conselho de meio ambiente estão presentes. A Figura 1 apresenta os principais requisitos para habilitação dos municípios nos estados.

Figura 1 - Principais requisitos exigidos pelos estados para habilitação dos municípios.

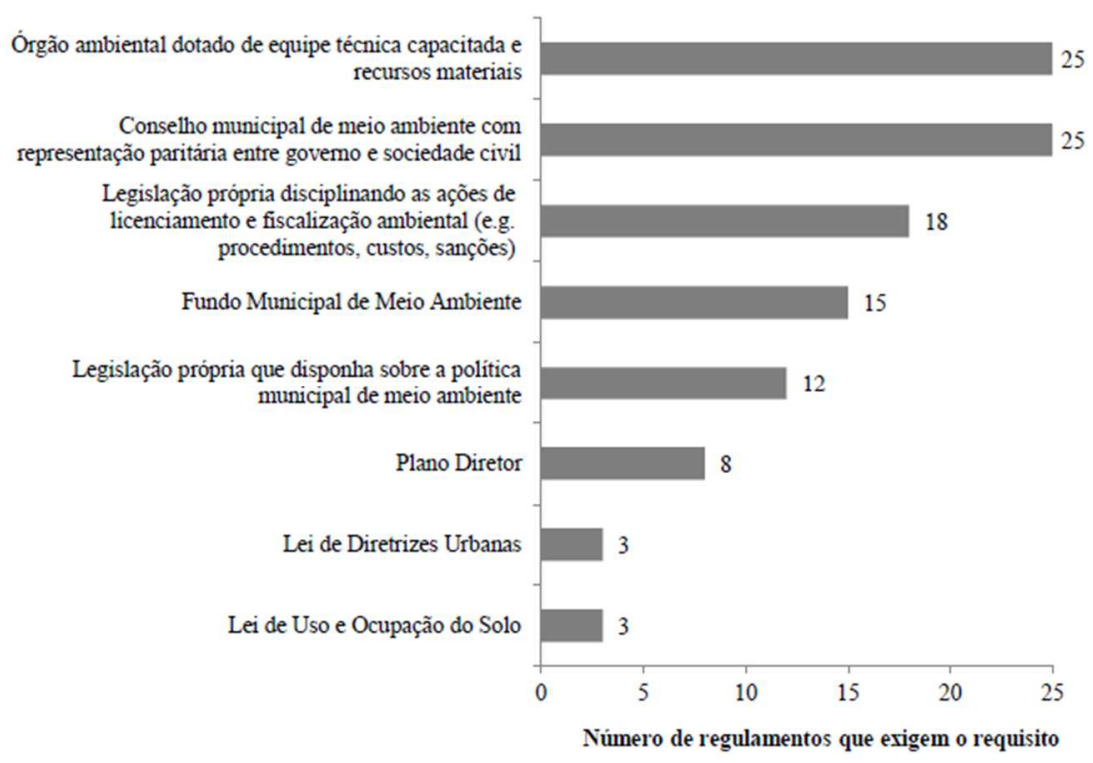

Fonte: Nascimento (2018, p.52).

A resolução do Conselho Estadual do Meio Ambiente do Ceará - COEMA, no 07 de setembro de 2019, estabelece no seu artigo 6으 os componentes que devem ser atendidos pelos órgãos ambientais municipais, que buscam se tornarem aptos a executar o licenciamento ambiental. Os critérios são: órgão ambiental capacitado; política municipal de meio ambiente prevista em legislação específica; conselho municipal de meio ambiente em atuação, consistente em instância colegiada, normativa e deliberativa de gestão 
ambiental, com representação da sociedade civil organizada paritária à do Poder Público; legislação que discipline o licenciamento ambiental municipal; equipe multidisciplinar de nível superior para analisar o licenciamento ambiental; e, equipe de fiscalização e de licenciamento formada por servidores públicos efetivos de nível superior (CEARÁ, 2009).

Atendidos os critérios e havendo o reconhecimento por parte do Conselho Estadual de Meio Ambiente, que por sua vez encaminhará cópia da referida comunicação à Secretaria Estadual de Meio Ambiente - SEMA e a Superintendência Estadual de Meio Ambiente - SEMACE, o município encontrase apto a realizar o licenciamento ambiental a partir do seu sistema próprio de gestão ambiental no Estado do Ceará.

\subsection{CARACTERIZAÇÃO SOCIOAMBIENTAL DE PACATUBA}

O município de Pacatuba está localizado na porção Nordeste do Estado do Ceará e pertence à Bacia Hidrográfica Metropolitana (CEARÁ, 2009, p.17). A média anual pluviométrica varia de $800 \mathrm{~mm}$ a $1400 \mathrm{~mm}$. As temperaturas variam de entre $26{ }^{\circ} \mathrm{C}$ e $28^{\circ} \mathrm{C}$, em um clima caracterizado como tropical quente subúmido. As vegetações predominantes são a do Complexo Vegetacional da Zona Litorânea e a Caatinga Arbustiva Densa, além das Florestas Subperenifólia Tropical Pluvio-Nebular (Mata Úmida) e a Floresta Subperenifólia Tropical Pluvial (CEARÁ, 2009, p.18).

Pacatuba possui uma base econômica variada, com a presença dos três setores econômicos. No setor primário se destacam a produção agrícola com a presença de lavouras temporárias (cana de açúcar, feijão, mandioca, melancia, melão e milho) e permanentes (banana, castanha de caju, coco da baia, laranja, mamão, manga e maracujá). A extração vegetal é representada pelos subprodutos da carnaúba. A pecuária se destaca pela criação de bovinos, equinos, suínos, caprinos, ovinos e galináceos (PAIVA, 2015, p. 27). Destaca-se no extrativismo mineral, a extração de rochas ornamentais, rochas para cantaria, brita, placas para fachada e usos diversos na construção civil, notadamente no distrito de Monguba (BRASIL, 1998, p.7). 
No setor secundário Pacatuba apresenta um pujante parque industrial e é composto por empresas têxteis e de confecção, de bebidas, embalagens e outras. No setor terciário a atividade turística é representada pelo turismo religioso, histórico, ecoturismo e de aventura. Na prestação de serviços e comércio, destacam-se as atividades de transporte e armazenamento, além dos setores varejistas e atacadistas (PAIVA, 2015, p.41).

A ocupação do espaço territorial de Pacatuba também apresenta uma forte alteração do solo, devido a instalação de loteamentos e conjuntos habitacionais. O produto interno bruto - PIB no ano de 2017 foi $\mathrm{R} \$ 1$ 1.035.662,30, colocando-o na 19ำ posição em relação ao estado. A população do Município de Pacatuba foi estimada em 2019 em 83.432 habitantes (BRASIL, 2019).

\section{METODOLOGIA}

Este artigo aborda um estudo de caso, cujos dados em parte são qualitativos, de origem de eventos reais e que tem o objetivo de explicar, explorar ou descrever fenômenos atuais inseridos em seu próprio contexto, fornecendo conhecimentos profundos (YIN, 2009 apud BRANSKI; FRANCO; LIMA JR., 2010).

Segundo Sousa (2018), a abordagem da pesquisa que possui caráter qualitativo e que foi adotada neste trabalho, permite a articulação entre dados a serem estatisticamente tratados, mas também dados descritivos, e dessa maneira corrobora com os autores acima, em relação a possibilidade de uma discussão mais profunda e detalhada, considerando a dinâmica da relação com o meio.

Em relação ao levantamento das informações que antecederam a criação do órgão ambiental municipal, incluindo o Fundo do Meio Ambiente, o Conselho de Meio Ambiente, bem como a descrição dos desafios da implantação da Autarquia de Meio Ambiente de Pacatuba - AMAPA, estas foram compiladas a partir das experiências do presidente e coordenador de licenciamento da AMAPA, também autores deste artigo, cujo segundo acompanhou o 
desenvolvimento da gestão ambiental em Pacatuba, desde 2011, quando se tornou servidor efetivo municipal.

Quanto aos dados quantitativos do licenciamento, fiscalização e monitoramento ambiental apresentados neste trabalho, estes foram adquiridos a partir da listagem de processos, referente ao período 2017-2019, que foram encaminhamos à Autarquia para análise. Nessa lista constavam os tipos de licenças requeridas: Licença Prévia-LP, Licença de Instalação-LI, Licença de Operação-LO, Licença Mineral-LM e Autorização Ambiental-AA, cujos valores apresentados foram levantados, tabulados em planilha do tipo Excel, a partir da base de dados de arrecadação do município de Pacatuba.

Em relação aos dados referentes à produtividade, estes foram obtidos a partir da análise dos relatórios de produção, gerados pela própria AMAPA, que tiveram o intuito de atender ao princípio da publicidade para os munícipes e o Conselho de Meio Ambiente de Pacatuba.

Ademais, para a discussão dos resultados, adotou-se a abordagem metodológica do tipo indutiva, que de acordo com Diniz e Silva (2008) as informações coletadas conduzem a conclusões prováveis e permitem ao pesquisador a partir de uma lei geral, as constatações particulares sobre os fenômenos observados.

\section{RESULTADOS E DISCUSSÃO}

\subsection{PRELÚDIO DE IMPLANTAÇÃO DO ÓRGÃO MUNICIPAL DE GESTÃO DO MEIO AMBIENTE DE PACATUBA}

A partir da compilação das informações, identificou-se que apenas no ano de 2013 houve algum interesse da administração pública de Pacatuba pela gestão ambiental municipal. Nesse período, o município de Pacatuba, representado pela Secretaria de Infraestrutura e Meio Ambiente, contratou uma consultoria, que deveria apresentar ao final dos trabalhos, todos os elementos necessários para o funcionamento administrativo e legal do futuro órgão de 
gestão ambiental municipal. Assim, entre as opções apresentadas para a construção administrativa do novo órgão, escolheu-se a autonomia administrativa do órgão como principal característica.

Esse período corrobora com a avaliação de Abreu (2016, p.154), que identificou o aumento do número de trabalhos científicos sobre licenciamento ambiental descentralizado, a partir das análises de 41 publicações referente à década de 2000, após a emissão da LC nำ140/2011.

Invariavelmente, com o foco de garantir a maior autonomia administrativa, o órgão foi pensado com bases na administração indireta e mais precisamente como uma autarquia ${ }^{8}$. O estado do Ceará já apresentava instituídos alguns outros órgãos, com o mesmo modelo administrativo, em importantes municípios, incluindo Eusébio e Sobral, sendo este último o que subsidiou a construção de alguns marcos legais para Pacatuba.

Quanto ao processo de produção dos instrumentos legais, isso ocorreu de forma relativamente rápida, pois o município de Pacatuba já apresentava vasto conteúdo legal, tais como o Fundo de Meio Ambiente e o Conselho de Meio Ambiente. Desse modo, a consultoria concentrou os seus trabalhos para a adequar e produzir a política de meio ambiente e a lei de criação da autarquia de meio ambiente. Contudo, a transição entre gestões impediu a implantação do órgão de fato.

\subsection{FUNDO DE MEIO AMBIENTE}

O Fundo de Meio Ambiente de Pacatuba - FMMA, criado pela Lei Municipal no 917, de 18 de janeiro 2008, administrado pelo Conselho de Meio Ambiente de Pacatuba - COMUMA foi criado para gerir e criar recursos para o financiamento de planos e projetos que visem ao uso racional dos recursos ambientais, à prevenção de danos ambientais e à promoção da ambiental.

\footnotetext{
${ }^{8}$ É formada pelo conjunto de pessoas jurídicas vinculadas à administração direta, dotadas de personalidade jurídica própria (tem vida própria), possuindo competência para o exercício de atividades administrativas, de forma descentralizada.
} 
As fontes orçamentárias são provenientes de: dotações orçamentárias e créditos adicionais; taxas e tarifas ambientais, bem como penalidades pecuniárias delas decorrentes; transferências de recursos da União, do Estado ou de outras entidades públicas e privadas; acordos, convênios, contratos e consórcios, de ajuda e cooperação institucional; doações, legados, contribuições em dinheiro, valores, bem móveis e imóveis, recebidas de pessoas físicas ou jurídicas, públicas ou privadas, nacionais ou internacionais; multas cobradas por infrações às normas ambientais, na forma da lei; rendimentos de qualquer natureza, que venha a auferir como remuneração, decorrente de aplicações de seu patrimônio; e, outros destinados por lei.

A atual gestão da AMAPA alimenta o fundo com recursos advindos, principalmente das taxas de licenciamento ambiental, estabelecidas na Portaria no. 008/2017, que definiu as normas técnicas e administrativas, necessárias à regulamentação do sistema municipal de licenciamento, das atividades utilizadoras de recursos ambientais.

Em decorrência da autonomia administrativa da AMAPA, criada através da Lei Municipal no. 1.195/2013, ela possui o Cadastro Nacional de Pessoa Jurídica próprio e uma respectiva conta criada que recebe recursos, principalmente, de multas ambientais.

\subsection{CONSELHO DE MEIO AMBIENTE}

Conselho Municipal de Urbanismo e Meio Ambiente de Pacatuba COMUMA, criado pela Lei no 0836, de 20 de julho de 2005, possui a incumbência de incentivar e garantir a preservação dos processos ecológicos, objetivando o fomento, a promoção e a manutenção de um ambiente ecologicamente equilibrado.

O Conselho tem a competência de ser instância colegiada, deliberativa, recursal, e de assessoramento ao poder Executivo, sobre questões ambientais e correlatas no município. Entre suas competências podemos destacar: propor diretrizes para política Municipal do Meio Ambiente; avaliar, propor e definir padrões para técnicas, planos e ações relativas ao controle e a manutenção da 
qualidade do meio ambiente, tendo em vista o uso racional dos recursos ambientais, de acordo com a legislação pertinente, supletivamente ao Estado e à União; gerir e participar das decisões sobre a aplicação dos recursos destinados ao meio ambiente, propondo critérios para a sua programação e avaliando os programas, projetos, convênios, contratos e quaisquer outros atos que serão subsidiados pelo mesmo.

Ainda em relação ao COMUMA, este enfrenta os desafios comuns aos diversos órgãos colegiados, principalmente, quanto à formação do quórum durante as plenárias como observado por Nunes, Philippi e Fernandes (2012, p. 56-57), notadamente, para a sociedade civil.

De acordo com os relatos dos servidores, a existência do COMUMA nos primeiros anos foi conturbada pelo desalinhamento entre a função do Conselho e o seu órgão de assessoramento, a Secretaria de Infraestrutura e Meio Ambiente, em decorrência do distanciamento de prioridades, pois ela tinha maior afinidade com as atividades de obras do que gestão ambiental.

Esse desalinhamento tornou virtual a existência do Conselho, pois não se conseguia mobilizar a sociedade civil e nem o poder público, para formar quórum para as reuniões ou mesmo para o processo eleitoral. Esse processo somente foi interrompido, com a formação da Secretaria de Meio Ambiente e Urbanismo - SEMAM, em 2017, que tinha um viés alinhado com a função do COMUMA e possuía material e pessoal para a devida mobilização.

\subsection{IMPLANTAÇÃO DA AMAPA}

A Lei Municipal №. 1195/2013, de 04 de dezembro de 2013, criou a AMAPA. A criação em lei foi o único produto submetido e aprovado no legislativo, a partir da consultoria ambiental, que subsidiou a implantação da gestão ambiental municipal. No entanto, a criação de direito não representou a criação de fato, pois apenas em 2017, com a ascensão de uma nova gestão, houve a mobilização para instrumentalizar e executar a função da AMAPA.

A nova gestão compreendeu que o desenvolvimento de Pacatuba poderia ser acelerado com uma maior autonomia em relação ao licenciamento ambiental 
estadual. Essa motivação foi observada por $\operatorname{Nascimento~}(2018$, p.10) ao afirmar que a descentralização, de forma geral no Brasil, permite uma atuação mais rápida dos líderes locais, o controle mais efetivo da população e cria a expectativa de redução da carga de processos dos estados, ao transferir aos municípios as atividades de licenciamento de impacto local.

Contudo, foi necessária a continuidade da produção do arcabouço legal para garantir o pleno funcionamento da autarquia. Logo, foi elaborado 0 regimento interno da autarquia como exigido pelo artigo $n^{\circ}-25$ da lei de criação da AMAPA.

Outro importante instrumento legislativo criado foi a Política Ambiental de Meio Ambiente de Pacatuba, através da Lei oㅜ 1.388, de 22 de março de 2017, que tem por pressuposto assegurar que as atividades e ações de impacto ambiental local, além de todos os vieses da gestão ambiental tenham o controle por parte do município.

A política de meio ambiente ainda assegurou a adoção da visão local da gestão ambiental, ao conciliar os interesses do município com a legislação suplementar existente. O seu conteúdo apresenta soluções relativas ao licenciamento, monitoramento e fiscalização ambiental, além de temas específicos relativos à educação ambiental, unidades de conservação, controle urbano entre outros. Esses assuntos considerados, permitem uma abordagem holística do tema ambiental.

Após análise, verificou-se que Pacatuba possuía todos os critérios para a implantação de órgão ambiental municipal, conforme a LC no 140/2011. Segundo os levantamentos de Nascimento (2018, p.53), avaliou-se que esses critérios não são uniformes nos estados da federação.

Ressalta-se que antes da LC entrar em vigor, Pacatuba possuía a vantagem em relação às normas, pois houve produção legislativa, ao longo de mais de uma década, que se iniciou com a adequação do município ao Estatuto das Cidades, Lei no 10.257, de 10 de julho de 2001. No entanto, reitera-se que não houve a atenção à revisão dessas legislações o que acarreta dificuldades em adequar as demandas hodiernas e a legislação desatualizada. 


\subsection{LICENCIAMENTO AMBIENTAL}

Dentre o maior número de publicações existentes, relacionada à gestão ambiental local, destaca-se o licenciamento (NASCIMENTO, 2018, p.26). Esse direcionamento dos estudos pode ser compreendido como reflexo de ser um meio de arrecadação e de aproximar o controle político municipal sobre o tema.

No município de Pacatuba o licenciamento é disposto pelas Leis $\mathrm{n}^{0}$ 1.195/2013, e pela Lei no 1.446/2017. No entanto, a regulamentação ocorreu através da Portaria no 008/2017, de 25 de agosto de 2017, que estabeleceu o modelo de pedido, análise, cobrança e recepção da licença no processo de licenciamento ambiental. O município de Pacatuba iniciou suas atividades de licenciamento em plenitude depois do aceite do COEMA e o envio desse aceite a SEMACE, indicando que o município atendia aos pré-requisitos presentes na Resolução COEMA № 02/2016, revogada pela Resolução COEMA № 07/2019.

A recepção ao novo órgão ambiental municipal foi satisfatória por parte dos servidores municipais, ao se considerar a efetividade das ações por parte da SEMACE, durante o período inicial de transição do licenciamento, pois ela permitiu de forma imediata, o encaminhamento dos novos processos à AMAPA, quando do requerimento do licenciamento ambiental relativos ao impacto local em Pacatuba.

Por outro lado, a divulgação através da internet, no endereço do site do órgão estadual sobre o informativo prévio da listagem dos municípios aptos ao licenciamento ambiental local, foi um meio fundamental, para que a comunidade tivesse acesso à existência da AMAPA. O relato da boa integração entre o ente estadual e o municipal para transferência dos processos de licenciamento também foram relatados por Tassi e Kühn (2015, p. 127).

A AMAPA segue o modelo preconizado pelas resoluções CONAMA no 01/86 e n 237/97 para o sistema de licenciamento ambiental. Assim, adota o modelo trifásico com a licença prévia - LP, de instalação - LI e operação - LO. A 


\section{¿unisul}

figura 3 abaixo apresenta o número de licenças ambientais emitidas durante os anos de 2017 a 2019, além do valor total arrecadado em cada ano.

Figura 3 - Evolução da distribuição do tipo de licença ambiental pela AMAPA9,10 e arrecadação total por ano.

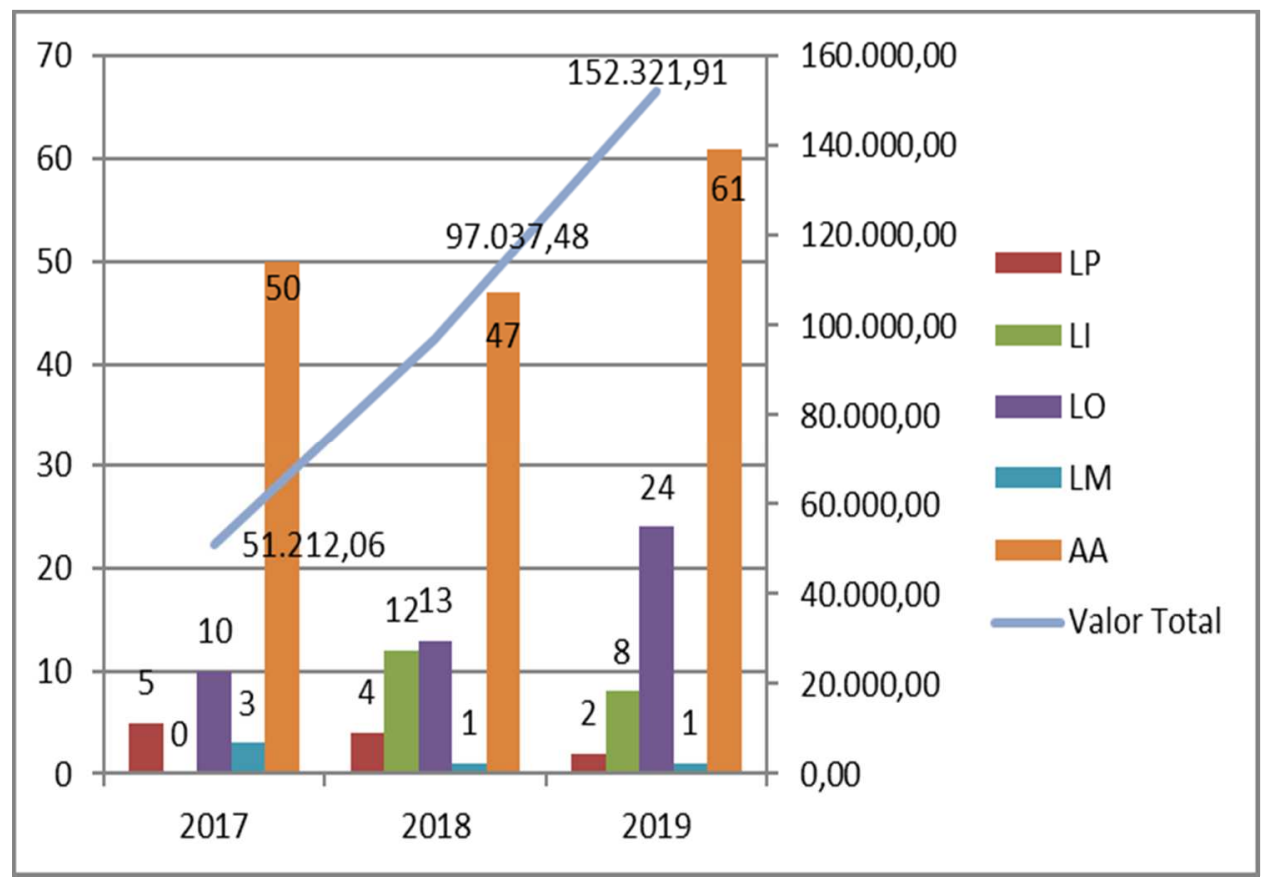

Fonte: Autores

Silva (2017) e Rocha (2020) ao analisarem os processos de licenciamento ambiental, respectivamente, nos municípios cearenses de Eusébio e Maracanaú, assim como Pacatuba localizados na Região Metropolitana de Fortaleza, identificaram a adoção de um modelo de licenciamento, cujas licenças simplificadas se destacaram de forma significativa em relação às demais. Os municípios de Maracanaú e Eusébio nos anos de 2013, 2015 e 2016 mantiveram acima de $50 \%$ dos totais de licenças únicas, que exigem análises mais simplificadas. A adoção de modelos simplificados permitiu superar gargalos que

\footnotetext{
${ }^{9}$ Licença Mineral / LM - Emitida pela autoridade municipal dando anuência para área a ser explorada como parte do Processo do Departamento Nacional de Produção Mineral - DNPM.

${ }^{10}$ Autorização Ambiental / AA - Modelo adotado em Pacatuba de tipo de licença simplificada pelo porte, temporalidade e impacto considerados baixo.
} 
são identificados nos órgãos estaduais (NASCIMENTO e FONSECA, 2017, p. 162).

Junto a isso, a municipalização da gestão ambiental tem a vantagem da equipe técnica possuir grande compreensão da área, onde os processos de licenciamento estão relacionados e à reduzida necessidade de deslocamentos em demasia e, assim, não ocorre a demanda de tempo para conhecer a área do impacto (DORNELES, 2011, p. 104).

Com relação aos números anuais dos documentos emitidos pela AMAPA, obteve-se 68,77 e 96, correspondentes aos anos de 2017, 2018 e 2019, respectivamente. Esse resultado crescente no período observado, reflete à demanda que foi sendo repassada de forma gradual pelo órgão estadual e ao mesmo tempo, o reconhecimento pela população local das ações da AMAPA, em relação a sua capacidade de licenciamento e o atraente modelo de gestão a novos empreendedores ou mesmo os antigos, que já haviam desistido de investimentos pela morosidade do Estado para trazer recursos ao município.

Considerando que o número de licenças requeridas foi crescente para o período, esse resultado também representa o aumento de valores expressivos arrecadados, assim, obteve-se o incremento que ultrapassou $100 \%$ do valor, quando se compara dois períodos consecutivos, ou seja 2017-2018 e 20182019.

Cabe destacar que, os resultados financeiros expressivos acima mencionados, para o Município de Pacatuba, foram decorrentes principalmente às atividades de instalação de condomínios e loteamentos.

As licenças que correspondem ao modelo trifásico (LP, LI e LO) apresentam como destaque o maior número de atividades que solicitaram a regularização nas etapas de instalação ou operação. No entanto, ressalta-se que mesmo não havendo a emissão de alguma licença, respectiva a determinada fase, há a cobrança do respectivo valor da licença por haver a avaliação técnica dos fundamentos da respectiva licença juntamente as demais licenças.

Em detrimento da morosidade do modelo trifásico e a complexidade inerente foi construído um modelo simplificado para empreendimentos de baixo 
impacto. A adoção de modelos simplificados permitiu superar gargalos que são identificados nos órgãos estaduais (NASCIMENTO \& FONSECA, 2017, p. 162). Além das licenças, outra fonte de recursos foram os cadastros técnicos que são exigidos para a apresentação de determinados estudos ambientais, assim, para os anos de 2017, 2018 e 2019 foram, respectivamente, 7, 6 e 17 cadastros técnicos realizados.

É necessário ressaltar, que o ganho não foi exclusivamente financeiro, pois deve ser considerado ainda a autonomia em relação ao Estado, pois permite que o administrador possa dar maior atenção aos interesses locais, assim podendo haver uma melhor programação para obtenção de resultados sem estar subordinado ao Estado, que muitas vezes, é lento em relação ao processo de análise ambiental.

A operação vem paulatinamente agregando novos servidores a equipe que foi formada por servidores de carreira de outros órgãos da prefeitura para reduzir custos, que são identificados em outros órgãos da própria prefeitura e que se dispõe a enfrentar os novos desafios apresentados. Assim hoje o corpo técnico do licenciamento é composto por quatro analistas ambientais: um engenheiro civil, um engenheiro agrônomo, uma geógrafa (única contratada e respectivamente coordenadora de licenciamento ambiental), e, finalmente, um tecnólogo em gestão ambiental, além de engenheiro de pesca.

É válido enfatizar que, buscando maior eficiência, todos tem formação de pós-graduação totalizando oito (8) especializações e dois (2) mestrados, distribuídos entre os servidores. Esse número de analistas condiz com resultados obtidos por Nascimento e Fonseca (2017, p.160), que identificaram entre 84 municípios analisados, que a equipe responsável pelo licenciamento ambiental é menor que cinco (5) pessoas em $37 \%$.

Contudo, há dificuldades relativas à formação continuada dos servidores, pois não há um programa de reciclagem e aprimoramento integrado à rotina da AMAPA. Isso acarreta eventuais descompassos entre as ações da AMAPA e o melhor estado da arte, no que se refere à adoção de uma visão holística da legislação existente. 
Outro desafio se refere à satisfação financeira dos servidores, que observam disparidades, quando comparam os ganhos salariais de servidores de órgãos ambientais de Itaitinga e São Gonçalo do Amarante. Estes municípios realizaram concursos no ano de 2019 com salário inicial acima do alcançado pelos servidores da AMAPA, sendo assim, verifica-se a necessidade de expressivas vantagens e gratificações para equilibrar o valor. No entanto, cabe ressaltar que uma alternativa que já foi aplicada com sucesso aos fiscais ambientais de Pacatuba foi a incorporação da gratificação por produtividade.

\subsection{MONITORAMENTO AMBIENTAL}

O monitoramento ambiental é um desdobramento, essencial da gestão ambiental municipal, pois permite ao município acompanhar a evolução dos procedimentos e ações realizadas por ele próprio e pelos usuários (FLORENCIO, 2010, p.1). Contudo, é um tema de baixa aderência, em decorrência da sua vinculação, muitas vezes reducionista, aos processos de licenciamento ambiental e fiscalização, tornando-o um coadjuvante da gestão ambiental.

A relação do monitoramento ambiental com o processo de licenciamento ocorre pela necessidade de se observar e mensurar a adoção de medidas preventivas e condicionantes descritas na licença ambiental.

No entanto, é necessário compreender que atualmente há o deslocamento da utilização desse instrumento de controle do estado para uma operação autônoma pelo empreendedor, através do automonitoramento.

A abordagem do automonitoramento como forma de controle da atividade, e não de um procedimento, permite monitorar sem sobrecarregar a estrutura do estado (FLORENCIO, 2010, p.23). O município, apesar de não ser taxativo em sua legislação sobre esse modelo adota-o de forma a poder permitir que a equipe técnica possa direcionar tempo e recursos a apenas as atividades que apresentam incoerências observadas no controle final.

Os instrumentos de automonitoramento adotados em Pacatuba são apresentados ao empreendedor como condicionante para manutenção da 
respectiva licença ambiental, ou outro instrumento legal, concedido ao empreendedor. Os principais modelos adotados são o Relatório de Acompanhamento e Monitoramento Ambiental - RAMA e o Relatório Simplificado de Controle de Resíduos e Efluentes.

A cobrança do RAMA é anual e deve ser apresentado juntamente com toda a documentação comprobatória (fotos, recibos, relatórios, dentre outros), que subsidiem as informações apresentadas. Para o ano de 2017, obviamente, não houve nenhuma arrecadação, devido a inexistência de processos anteriormente licenciados. Porém, relativos aos anos de 2018 e 2019 obteve-se, respectivamente, 6 e 8 processos. Os valores arrecadados para cada ano foram, respectivamente, $R \$ 10.319,49$ e $R \$ 27.567,59$.

Em relação ao Relatório Simplificado de Controle de Resíduos e Efluentes, até a data de produção desse trabalho nenhum relatório simplificado foi apresentado.

Obviamente, no primeiro ano de operação da AMAPA não houve recursos advindos da análise de processos de automonitoramento, no entanto já nos anos seguintes houve sólida ampliação de arrecadação, sendo que há enorme potencial para a ampliação, pois a cada novo empreendimento ou atividade que tenha a mesma condicionante será possível arrecadar periodicamente esses valores.

No entanto, há dois desafios para continuidade do processo de regularização: o primeiro é continuar a identificar esses empreendimentos; e o segundo, e mais desafiador, é construir nesses empreendedores, que são identificados após anos de operação à margem da lei, a compreensão que o licenciamento é importante e um ganho para a sociedade.

Por outro lado, atualmente, há uma limitação para alcançar o objetivo do controle ambiental através do automonitoramento, pois há dificuldade de acompanhar os prazos dos processos e procedimentos pendentes, pois a ausência de informatização, dificulta a análise, que ocorre de forma manual ou quando o empreendedor busca informações relativas ao processo. Esse problema é reduzido em parte, em Pacatuba, pois a mesma equipe que executa 
o processo de licenciamento é encarregada do monitoramento, assim há muita familiaridade com o processo como um todo.

\subsection{FISCALIZAÇÃO AMBIENTAL}

A fiscalização é o mais dinâmico dos instrumentos de controle do Estado e constitui um dos pilares da gestão ambiental municipal. Ela ocorre tanto de forma corretiva quanto preventiva, assim, notoriamente é a mais visível faceta dos órgãos ambientais à população.

Em Pacatuba a fiscalização é aplicada de forma a garantir o controle, porém sem ser necessariamente uma ferramenta para arrecadação, uma vez que se prioriza a recuperação ambiental. Esse objetivo é alcançado com a garantia de descontos que preveem até $90 \%$ ou mesmo inexigibilidade da medida pecuniária, quando há a recuperação total do impacto negativo.

Verificou-se que a principal infração detectada foi ausência de licenciamento ambiental e apresentou uma oscilação no ano de 2018, que não pode ser facilmente explicada. Por ter sido um ano eleitoral e isso se repercute num cenário que tornou mais melindrosa as ações de fiscalização.

Outro elemento que teve significativa influência foi a mudança na estrutura e equipe, pois foi aglutinada a autarquia de meio ambiente e a secretaria de meio ambiente e houve redução no número de técnicos.

Em relação arrecadação, referente aos anos de 2017, 2018 e 2019, os valores respectivamente são: $R \$ 19.263,31,5.863,38$ e $R \$ 43.903,35$. Outro valor que merece destaque são os recursos advindos das ações de compensação ambiental, pela supressão vegetal, para uso alternativo do solo ${ }^{11}$, que permitiram a arrecadação nos anos de 2017, 2018 e 2019, respectivamente, de $\mathrm{R} \$ 13.647,17, \mathrm{R} \$ 4.047,46$ e 37.234,31. Grande parte desses valores obtidos foram resultados de empreendimentos imobiliários.

\footnotetext{
${ }^{11}$ Lei n ${ }^{\circ}$ 12.651/2011: Art. $3^{\circ}$ - Inciso VI: substituição de vegetação nativa e formações sucessoras por outras coberturas do solo, como atividades agropecuárias, industriais, de geração e transmissão de energia, de mineração e de transporte, assentamentos urbanos ou outras formas de ocupação humana.
} 
De certo modo, a municipalização do licenciamento também pode tornar o ato de fiscalizar melindroso, devido aproximação com a população e muitas vezes, existem pressões sociais sobre a equipe. Fora essa relação de proximidade, em Pacatuba, há problemas administrativos quanto à composição da equipe, pois ela ainda não apresenta total competência para executar a atividade, pois a LC nº 140/2011, apesar de não exigir uma formação específica da equipe, delega à regulamentação do Estado a exigência de que seja de nível superior.

Contudo, esse processo não anula a atividade, pois os servidores são fiscais efetivos, possuem formação técnica e as suas atribuições encontram-se tanto na legislação de controle urbano, quanto ambiental municipal. Assim, a legalidade da atividade é lastreada tanto pela política de meio ambiente quanto pela lei orgânica municipal. A solução para um enquadramento, tomado por base a Resolução COEMA no 07/2019 será um concurso para fiscais de nível superior.

\section{CONCLUSÃO}

O desafio da municipalização da gestão ambiental alcançou um novo patamar ao ser regulamentado o artigo 23 da CRFB/88 com a LC no 140/2011. Não há, a priori, empecilhos legais para que os municípios assumam a responsabilidade sobre o meio ambiente. No entanto, segundo os nossos resultados, há um vale de desafios até alcançar a plena autonomia que a LC noㅡ 140/2011 oferece;

Entre esses desafios para os municípios a superação dos critérios técnicos exigidos pelos conselhos estaduais de meio ambiente para formação de equipes qualificadas e com a disponibilidade de instrumentos adequados é relativamente simples em comparação ao maior desafio que é o interesse político;

A construção da AMAPA exemplifica com grande clareza como a ausência de interesse político inviabiliza a aplicação da municipalização da gestão ambiental. Segundo nossos resultados, desde o ano 2013 havia interesse administrativo e os instrumentos (legal, pessoal e técnico) para a construção da 
autarquia de meio ambiente municipal, no entanto sem interesse político se passaram quatro (4) anos até se sobrepujar o comodismo administrativo de manter sobre a égide do Estado as soluções de impacto local;

Os desafios apontados nos nossos resultados e relacionados ao pessoal são: qualificação contínua dos servidores, correção salarial, alcançarem maior representatividade entre a população, modificar a própria estrutura da administração pública para uma versão mais sustentável;

Contudo, a adoção da municipalização da gestão ambiental traz grande potencial administrativo e político em decorrência da autonomia em relação ao Estado, assim o município percebe novas fontes de arrecadação e ganha novos caminhos de negociação com a população;

Em Pacatuba, os valores pecuniários arrecadados se mostraram vultosos, pois eram valores que não existiam, pois se destinavam ao Estado, e ao se adotar uma equipe com servidores "da casa" não onerou em demasia a prefeitura ao construir o novo órgão.

\section{REFERÊNCIAS}

ABREU, E. L. Municipalização do licenciamento ambiental: análise comparada de experiências nos Estados de Minas Gerais e Piauí. Ouro Preto. Dissertação (Mestrado em Engenharia Ambiental) - UFOP, 2016. Disponível em: <https://www.repositorio.ufop.br/handle/123456789/7567>. Acesso em: 06 de fev. 2020.

ALENCAR, S.K.R P. Municipalização do Licenciamento Ambiental: tipologias de atividades impactantes, potencialidades e fragilidades do processo.2018.81f. Dissertação (Mestrado em Engenharia Ambiental) Universidade Federal Rural de Pernambuco, Recife, 2018. Disponível em: <https://repositorio.ufba.br/ri/handle/ri/28735>. Acesso em 30 abr. 2021.

ARAÚJO, C.L.P. Descentralização da Gestão Ambiental Pública: o licenciamento ambiental municipalizado em Araraquara-SP. Dissertação (Mestrado em Gestão de Organização e Sistemas Públicos) Universidade Federal de São Carlos, São Carlos, 166p. 2019. Disponível em: <https://repositorio.ufscar.br/handle/ufscar/11938>. Acesso em 30 abr. 2021.

BRASIL. IBGE. Disponível em: <https://cidades.ibge.gov.br/brasil/ce/pacatuba/ panorama>. 2019. Acesso em 03 de fev. 2020. 


\section{GESTÃO \& SUSTENTABILIDADE AMBIENTAL

BRASIL. Programa de Recenseamento de Fontes de Abastecimento por Água Subterrânea no Estado do Ceará. Ministério de Minas e Energia. CPRM. Fortaleza - Ceará. 14 p. 1998.

BRANSKI, R.M; FRANCO, R. A, C; LIMA JR., O, F. Metodologia de Estudo de Caso Aplicado à logística. In: Congresso de Pesquisa e Ensino em Transportes, XXIV ANPET, 2010, Salvador-Bahia. Disponível em:<https://www.researchgate.net/publication/27759882>. Acesso em: 27 de abr. 2021.

CARVALHO, M. A. Os desafios do Licenciamento Ambiental Municipal. Manaus. Artigo. XIV Congresso Brasileiro de Pesquisa e Pós-Graduação. Manaus. 2005. Disponível em: <http://www.publicadireito.com.br/conpedi/ manaus/arquivos/anais/XIVCongresso149.pdf>. Acesso em: 05 de fev. 2020.

CEARÁ. Curso gestão ambiental municipal Caderno 1 - Licenciamento Ambiental. Cartilha. Secretaria do Meio Ambiente do Estado do Ceará. Fortaleza - CE. 2017. Disponível em:<https://www.sema.ce.gov.br/wpcontent/ uploads/sites/36/2018/11/Licenciamento-Ambiental.pdf >. Acesso em: 05 de fev. 2020.

CEARÁ. Caderno Regional das Bacias Metropolitanas. Assembleia Legislativa do Ceará. 136 p. 2009.

DINIZ, C.R.; SILVA, I. B. Tipos de métodos e sua aplicação. Metodologia científica - aula 4. UEPB/UFRN. Campina Grande - RN. 20 p. 2008. Disponível em:

$<$ http://ead.uepb.edu.br/ava/arquivos/cursos/geografia/metodologiacientifica/Me t_Cie_A04_M_WEB_310708.pdf >. Acesso em: 05 de fev. 2020.

DORNELES, A. C. B. Licenciamento ambiental e a municipalização do meio ambiente. Revista Brasileira de Políticas Públicas. Artigo. Brasília. v. 1, n.3 número especial, p.103-121, dez. 2011. Disponível em: <https://www.jus.uniceub.br/RBPP/article/download/1216/1472>. Acesso em: 05 de fev. 2020.

FERLA, L. Municipalização da Gestão Ambiental: análise da organização gerencial e condições ambientais locais em municípios do Vale do Taquari, Rio Grande do Sul. Especialização. Universidade Federal do Rio Grande do Sul. Porto Alegre - RS. 2012. Disponível em: <https://lume.ufrgs.br/handle/10183/61961>. Acesso em: 05 de fev. 2020.

FILHO. J. S. C. O município e o enigma da competência comum constitucional. Artigo. Revista da Escola Superior da Magistratura do Estado de Santa Catarina, v. 20, n. 26. 28 p. 2013. Disponível em:<https://revista.esmesc.org.br/re/article/view/70>. Acesso em: 05 de fev. 2020.

FLORENCIO, E. O automonitoramento no Estado de Minas Gerais - Estudo de Caso: bacia hidrográfica do Rio Itabirito. Dissertação. Ouro Preto, MG. 115 


\section{GESTÃO \& SUSTENTABILIDADE AMBIENTAL

p. 2010. Disponível em: <https://www.repositorio.ufop.br/ handle/123456789/3044>. Acesso em: 17 de fev. 2020.

GOLDMEIER, V.B. Análise da Gestão do Licenciamento Ambiental Municipal no Estado do Rio Grande do Sul. Dissertação. Universidade Federal do Rio Grande do Sul, Porto Alegre, 141p. 2017. Disponível em:<https://lume.ufrgs.br/handle/10183/172727>. Acesso em: 30 abr. 2021.

MACHADO, L.B. Licenciamento Ambiental Municipal: uma análise das práticas e desafios na sua aplicação em municípios da Bahia. Dissertação (Mestrado em Meio Ambiente, Águas e Saneamento) Universidade Federal da Bahia, Salvador, 180p. $2018 . \quad$ Disponível em:< https://repositorio.ufba.br/ri/handle/ri/28735>. Acesso em: 30 abr. 2021.

MOURA, A. M. M. A questão federativa no licenciamento ambiental. In: COSTA, M. A.; KLUG, L. B.; PAULSEN, S. S. (Org). Licenciamento ambiental e governança territorial: registros e contribuições do seminário internacional. Rio de Janeiro: IPEA, 2017. Disponível em: < http://www.ipea.gov.br/portal/images/stories/PDFs/livros/livros/170619_livro_lic enciamento_ambiental.pdf>. Acesso em: 05 de fev. 2020.

NASCIMENTO, T.R. S. Impacto local, desafios nacionais: a descentralização do licenciamento ambiental na federação brasileira. Dissertação. Universidade Federal de Ouro Preto. Ouro Preto - MG. 114 p. 2018. Disponível em: <https://www.repositorio.ufop.br/handle/123456789/10006>. Acesso em: 05 de fev. 2020.

NASCIMENTO, T.; FONSECA, A. A descentralização do licenciamento ambiental na percepção de partes interessadas de 84 municípios brasileiros. Artigo. Desenvol. Meio Ambiente, v. 43, Edição Especial: Avaliação de Impacto Ambiental, p. 152-170, dezembro 2017. 2017. Disponível em:< https://revistas.ufpr.br/made/article/view/ 54177>. Acesso em: 06 de fev. 2020.

NUNES, M. R.; PHILIPPI, A.; FERNANDES, V. A atuação de Conselhos do Meio Ambiente na Gestão Ambiental Local. Artigo. Saúde Soc., São Paulo, v. 21, supl. 3, p. 48-60, 2012. Disponível em: $<$ http://www.scielo.br/pdf/sausoc/v21s3/05.pdf>. Acesso em: 11 de fev. 2020.

PAIVA, G.M.C. A Natureza, a Cultura e o Patrimônio como pilares da dinâmica turística de Pacatuba, CE. Fortaleza - CE. Dissertação. Mestrado Profissional em Gestão de Negócios Turísticos do Programa de Pós-Graduação em Geografia do Centro de Ciências e Tecnologia da Universidade Estadual do Ceará. 2015.

ROCHA, I. M. Análise do processo de Licenciamento Ambiental no Município de Maracanaú - CE. Instituto Federal do Ceará. Maracanaú - Ce. 73 p. 2020.

SILVA, F. V. E. Análise do licenciamento ambiental no município do Eusébio - CE. Monografia. Universidade Federal do Ceará. Fortaleza - CE. 50 p. 2017. 


\section{sunisul}

SOUSA, M. P. Perspectiva quali-quanti no método de uma pesquisa. Artigo. XII Encontro Internacional d/e Formação de Professores e Fórum Permanente de Inovação Educacional. Aracaju - SE. 14 p. 2018. Disponível em: <https://eventos.set.edu.br/index.php/enfope/article/view/8668>. Acesso em: 05 de fev. 2020.

TASSI, R. H.; KÜHN, D. D. Gestão ambiental municipal: diagnóstico do processo de licenciamento ambiental no município de Palmeira das Missões - RS. Artigo. Revista Gestão e Sustentabilidade Ambiental. Florianópolis, PR. V. 3, n. 2, p. 113-141. Out.2014/mar.2015. Disponível em:< http://www.portaldeperiodicos.unisul.br/index.php/gestao_ambiental/article/view /2140>. Acesso em: 05 de fev. 2020. 